\title{
APORTE PARA UNA BIBLIOGRAFÍA SOBRE REVISTAS CULTURALES ARGENTINAS DEL PERÍODO 1920-1930*
}

María del Carmen Grillo**

\begin{abstract}
Con este trabajo queremos realizar una contribución bibliográfica sobre los estudios dedicados a revistas culturales argentinas publicadas en Buenos Aires entre 1920 y 1930. La dispersión, el aislamiento y la escasa circulación de la investigación hemerográfica justifican el intento de recopilar y describir aquellos trabajos que se dedican a examinar las publicaciones periódicas. ${ }^{1}$
\end{abstract}

\section{Estudios panorámicos de revistas}

Los más importantes estudios totales de las revistas literarias argentinas son, en orden cronológico, el de René Lafleur, Sergio Provenzano y

* Texto leído por la autora en el Encuentro de Historia de la Prensa en Iberoamérica; Universidad de Guadalajara, septiembre 1999.

** Facultad de Ciencias de la Información, Universidad Austral, Buenos Aires.

${ }^{1}$ Advertimos que por nota irán las referencias bibliográficas, $\mathrm{y}$ que indicaremos entre paréntesis las correspondientes referencias a las citas. 
Fernando Alonso, el de José M. Otero, el de Nélida Salvador, Myriam Gover de Nasatsky y Elena Ardissone, y el de Washington Luis Pereyra.

Lafleur, Provenzano y Alonso, en Las revistas literarias argentinas. 1893-1967, ${ }^{2}$ exponen los rasgos característicos de cada publicación en el marco de descripciones de épocas, grupos y períodos. No se trata meramente de un registro, sino de un relato en el que las revistas tejen también una historia, una trama de rupturas, filiaciones, precedencias y continuidades. La producción hemerográfica aparece periodizada en cuatro etapas: 1893-1919, 1919-1939, 1940-1950, y 1951-1967. Se acompaña cada capítulo con una guía hemerográfica y se cierra el trabajo con un índice. ${ }^{3}$

Fuera del decenio 1920-1930, dos trabajos se abocan a las revistas de los últimos años. José M. Otero, en 30 años de revistas literarias argentinas (1960-1989), ${ }^{4}$ y Nélida Salvador, Myriam Gover de Nasatsky y Elena Ardissone, Revistas literarias argentinas. 1960-1990. Aporte para una bibliografia, ${ }^{5}$ registran la producción hemerográfica con descripciones de las publicaciones más importantes.

Hacia nuestros días aparece, y está en pleno proceso de edición, $L a$ prensa literaria argentina. 1890-1974, de Washington Luis Pereyra, de la que se han editado ya tres tomos que cubren el período 1890 -

${ }^{2}$ René Lafleur, Sergio D. Provenzano y Fernando P. Alonso, Las revistas literarias argentinas. 1893-1967, 1968, Buenos Aires, Centro Editor de América Latina. Se trata de la segunda edición aumentada de la obra (con 620 registros); la primera, publicada en Buenos Aires por Ediciones Culturales Argentinas en 1962, abarca el período 1893-1960 (con 386 registros). ${ }^{3}$ Mencionamos otro trabajo de dos de los autores anteriores: Héctor René Lafleur y Sergio Provenzano, "Las revistas literarias", en Capitulo. Historia de la literatura argentina, 1967, Buenos Aires, Centro Editor de América Latina, $\mathrm{n}^{\circ} 56, \mathrm{p} .1321-44$.

${ }^{4}$ José M. Otero, 30 años de revistas literarias argentinas (1960-1989). Introducción a su estudio, 1990, Buenos Aires, Catedral al Sur Editores.

${ }^{5}$ Nélida Salvador, Miryam Gover de Nasatsky y Elena Ardissone. Revistas literarias argentinas: 1960-1990. Aporte para una bibliografia, 1996, Buenos Aires, Fundación Inca Seguros. 
$1939 .^{6}$ Es una obra de consulta obligatoria para los estudios hemerográficos. Las revistas se ordenan cronológicamente, dispuestas en períodos. El primero (1890-1919) agrupa revistas de los llamados 'años dorados", "por considerar que se trata de un lapso de inusitada transformación de la Argentina, durante cuyo transcurso se lanza y promueve, de alguna forma, una cultura nacional" (t. III, p. 13) y el segundo (1920-1929), contiene las revistas del período denominado 'los años rebeldes', "porque tal es, sin duda, el signo de la época y la dirección de la literatura y las demás artes" (idem). El tercero (1930-1939), 'los años ideológicos', recoge las publicaciones literarias, y reseña las inquietudes del desarrollo de los regímenes corporativos, del nazismo y del fascismo, de las dictaduras, de los fusilamientos de los anarquistas, de la Guerra Civil Española, de los 'procesos de Moscú', de Stalin.

A ese primer orden le sigue el alfabético, dentro del período de cada década, que viene acompañada de una cronología de acontecimientos históricos y de obras publicadas, y un apéndice que registra otras publicaciones del período.

Los registros cuentan con gran cantidad de datos, $y$, cuando la obra es de importancia, con extractos de manifiestos, o con su transcripción completa. Acompañan ilustraciones y reproducciones de las portadas. ${ }^{7}$

Alejandro C. Eujanian resume en Historia de revistas argentinas. 1900-1950. La conquista del público ${ }^{8}$ un período rico en publicaciones y complejo en virtud de las relaciones entre "las revistas, el público,

${ }^{6}$ Washington Luis Pereyra, La prensa literaria argentina. 1890-1974, Buenos Aires, Librería Colonial, t. I, 1993; t. II, 1995; t. III, 1996.

${ }^{7}$ El proyecto total de Washington L. Pereyra (según expresa su título, "Hacia una interpretación de la literatura argentina. Sus revistas"), se divide en dos partes, de acuerdo con el esquema que anuncia en el tomo I: la primera, de 1890 a 1939 , hasta el comienzo de la Segunda Guerra Mundial; la segunda, de 1940 a 1974, hasta la asunción de Héctor J. Cámpora a la presidencia de la Nación.

${ }^{8}$ Alejandro C. Eujanian, Historia de revistas argentinas. 1900-1950. La conquista del público, 1999, Buenos Aires, Asociación Argentina de Editores de Revistas. 
los escritores y el mercado cultural" (p. 11). El autor considera el incremento del público lector y su especialización, y se aboca a ciertos géneros: no sólo a las revistas literarias, sino a las del espectáculo, las de humor, las de política y sociedad y las dirigidas al público femenino. Se trata de un trabajo de carácter general, de divulgación.

La Asociación Argentina de Editores de Revistas (AAER) ha publicado dos volúmenes de Historia de revistas argentinas, ${ }^{9}$ que recogen trabajos premiados en sendos concursos de monografías de revistas argentinas, con el propósito, según dijeron en la convocatoria al III Concurso de 1998, de "Ilenar aunque sea parcialmente un vacío en la historia del periodismo argentino desde hace medio siglo, que a diferencia del de casi todos los países de Occidente no registra aportes bibliográficos sobre esta materia".

El mismo hecho de que la AAER convoque a concurso sin restricción alguna (excepto que los trabajos no se dediquen a revistas ya estudiadas en el ámbito de este certamen) propicia la falta de organización: los estudios se aplican a distintos tipos de publicaciones -revistas, historietas, colecciones de novelas-, y con diferentes enfoques, puies no siempre abarcan la totalidad de números, sino que se ciñen a un tema 82 o un aspecto.

El Comité Argentino de Ciencias Históricas publicó en el número 4 de su revista Clío ponencias presentadas en las VI Jornadas de 1996, cuyo tema fue Las revistas y la historia. ${ }^{10} \mathrm{El}$ volumen reúne los trabajos de distintos paneles: "Las revistas de opinión", "Las revistas de

${ }^{9}$ V.A., Historia de revistas argentinas, Buenos Aires, AAER; t. I, 1995, t. II, 1997.

${ }^{10}$ Comité Argentino de Ciencias Históricas, Comité Internacional, Clio, 1997, Buenos Aires, $n^{\circ} 4$.

${ }^{11}$ Noemí Girbal de Blacha, Diana Quattrochi-Woisson, "Las revistas de debates y de combate: entre tradición política y empresa cultural", cit., p. 13-27; Aurora Ravina, "Nosotros: opinión y debate sobre cultura y política. Entre la Ley Sáenz Peña y la crisis de 1930", cit., p. 29-45; María Silvia Ospital, "Síntesis: artes, ciencias y letras", cit., p. 47-58; Florencia Ferreira de Cassone, "Claridad y el 6 de septiembre de 1930"; cit., p. 59-81; Marcelo Montserrat, "Criterio y una polémica doctrinal. El caso Maritain", cit., p. 83-96. 
REVISTAS CULTURALES ARGENTINAS

historia", "Las revistas extranjeras y su influencia en la cultura histórica argentina", "Las revistas políticas y jurídicas", 14 "Las revistas literarias" 15 "Las revistas y la formación de la conciencia nacional". 16

El CRICCAL (Centre de Recherches Interuniversitaires sur les Champs Culturels en Amérique Latine) edita América, ${ }^{17}$ publicación que ha dedicado a las revistas dos de sus números, a partir de los encuentros

${ }^{12}$ Emesto J. A. Maeder, "Revistas históricas en la segunda mitad del siglo XIX", cit., p. 99-110; María Cristina de Pompert de Valenzuela, "Un siglo de revistas históricas: las revistas universitarias, 1900-1950", cit., p. 111-20; María Silvia Leoni de Rosciani, "Las revistas históricas fuera del ámbito académico", cit., p. 121-38.

${ }^{13}$ Nilda Guglielmi, "Las revistas extranjeras y su influencia en la cultura histórica argentina", cit., p. 141-48; Hebe Clementi, "Tres revistas norteamericanas de historia que abren la cabeza", cit., p. 149-58; Eduardo Hourcade, "Sur en la encrucijada. Un observatorio de Francia en el Plata (1944-1946)", cit., p. 159-85.

${ }^{14}$ Enrique Zuleta Álvarez, "Cambio y permanencia en las revistas del nacionalismo argentino (1920-1940)", cit., p. 189-201; Néstor Tomás Auza, "Las revistas políticas de los siglos XIX y XX, 1810-1930", cit., p. 203-16; Alberto David Leiva, "Revistas jurídicas y cultura forense en el Buenos Aires del siglo XIX", cit., p. 217-29; Abelardo Levaggi, "Las revistas de Historia del Derecho", cit., p. 231-39.

${ }^{15}$ Emilia de Zuleta, "Hacia un mapa de las revistas literarias argentinas", cit., p. 243-56; Elena Baeza, "La revista Letras de Buenos Aires", cit., p. 257-64; Marta Elena Castellino, "Algunas revistas literarias argentinas y la formación del canon", cit., p. 265-85; Jaime Correas, "Las revistas literarias desde el interior. Tres casos de Mendoza", cit., p. 287-95.

${ }^{16}$ Armando R. Bazán, “Árbol. Revista catamarqueña de cultura. Un emprendimiento cultural abierto al noroeste", cit., p. 299-306; Hebe Carmen Pelosi, "La Revista de Derecho, Historia y Letras y el concepto de nación", cit., p. 307-21; Alicia Poderti, "Tarja: las revistas literarias y la identidad regional en el NOA", cit., p. 323-35.

${ }^{17}$ América. Cahiers du CRICCAL, París, Université de la Sorbonne NouvelleParis III, Presses de la Sorbonne Nouvelle, nos. IV-V, Le discours culturel dans les revues latino-américaines de l'entre deux guerres, y IX-X, Le discours culturel dans les revues latino-américaines de 1940 à 1970. 
internacionales de 1987 y 1990; respectivamente, Le discours culturel dans les revues latino-américaines de l'entre deux-guerres. 1919-1939, y Le discours culturel dans les revues latino-américaines (1940-1970). Los estudios se encuentran dispuestos por regiones y países (Caribe y América Central, Colombia y Venezuela, México, Perú, Río de la Plata, Chile). ${ }^{18}$

Orientados a revistas literarias de este período, contamos con tres trabajos: dos estudios de Nélida Salvador, titulados Revistas argentinas de vanguardia (1920-1930) ${ }^{19}$ (que ofrece una caracterización de las corrientes y las publicaciones vanguardistas), y "Las revistas de una época literaria: 'Florida-Boedo", 20 dedicado a la misma etapa. El tercer estudio corresponde a Eduardo Romano, "Las revistas argentinas (" de" vanguardia en la década de 1920","21 que distingue tres líneas: la de los 'primeros intentos' (Los Raros, Prismas, Proa), la de Martín Fierro y la de otras revistas 'más heterogéneas' (Inicial, Valoraciones y Revista de América).

Hacemos notar que, en la mayor parte de los casos, la expresión 'revistas literarias argentinas' se restringe a revistas de la ciudad de Buenos Aires, o las considera preferentemente.

${ }^{18}$ En lo que respecta a la Argentina, el volumen del período 1919-1939 reúne exposiciones sobre Inicial (1923), La Campana de Palo (1925), Contra (1933), Sur (1931-1989), Criterio (1928-), Revista del Instituto de Investigaciones Históricas "Juan Manuel de Rosas" (1939-1963), Los Pensadores (1922-1924) y Claridad (1926-1941), y Tecne (1942-1944).

${ }^{19}$ Nélida Salvador, Revistas argentinas de vanguardia (1920-1930), 1962, Buenos Aires, Universidad de Buenos Aires.

${ }^{20}$ Nélida Salvador, "Las revistas de una época literaria: 'Florida-Boedo"”, en Testigo. Revista de literatura y arte, Buenos Aires, $\mathrm{n}^{\circ} 3$, julio-agostoseptiembre de 1966, p. 40-4.

${ }^{21}$ Eduardo Romano, "Las revistas argentinas de vanguardia en la década de 1920", en Cuadernos Hispanoamericanos, Madrid, $\mathrm{n}^{\circ} 411$, septiembre 1984 , p. $177-200$. 
REVISTAS CULTURALES ARGENTINAS

\section{Estudios dedicados a una publicación}

En la investigación sobre revistas argentinas, hay una enorme cantidad de estudios dedicados al examen de una sola publicación. Nos ceñimos al período 1920-1930, y al campo de las revistas culturales.

Por una parte, la noción de 'revista cultural' aparece como problemática para distinguir entre las que son publicaciones culturales propiamente dichas y las que no lo son, desde la proposición de las revistas mismas. Boyd G. Carter resume esta dificultad, en Las revistas literarias de Hispanoamérica: ${ }^{22}$

Al parecer, todo aspecto de la civilización contemporánea que se niega a la fácil definición, todo desarrollo nuevo que se aparta del sendero conocido, esto es cualquier actividad o manifestación social, económica, política, deportiva, etnográfica, que busque distinción genérica, acude, y hasta se precipita, así lo parece por lo menos, a ponerse bajo la prestigiosa protección del término 'cultural' o cultura. (p. 24)

Por otra parte, la expresión 'revista cultural' suele restringirse a las publicaciones estrictamente literarias. De esta manera, entonces, la denominación permite tanto el gesto de la inclusión como el de la exclusión.

No nos ceñiremos a la segunda forma de considerar lo cultural como exclusiva manifestación de lo literario. Sin duda, aquellos que abordan en profundidad estas publicaciones permiten establecer articulaciones entre ellas y la historia cultural de un país; Beatriz Sarlo, en "Intelectuales y revistas: razones de una práctica" caracteriza la importancia de las publicaciones periódicas:

${ }^{22}$ Boyd G. Carter, "Revistas y periódicos: enfoques y problemas del investigador", en Las revistas literarias de Hispanoamérica. Breve historia y contenido, 1959, México, Ediciones De Andrea, p. 13-37. 
[...] las revistas abren una fuente privilegiada para lo que hoy se denomina historia intelectual. Instituciones dirigidas habitualmente por un colectivo, informan sobre las costumbres intelectuales de un período, sobre las relaciones de fuerza, poder y prestigio en el campo de la cultura, relaciones y costumbres que no repiten de manera simple las que pueden leerse en los libros editados contemporáneamente. Resistiéndose a una perspectiva crítica formalista, las revistas parecen objetos más adecuados a la lectura socio-histórica: son un lugar y una organización de discursos diferentes, un mapa de las relaciones intelectuales, con sus clivajes de edad e ideologías, una red de comunicación entre la dimensión cultural y la política. ${ }^{23}$

No son ociosas las consideraciones epistemológicas y metodológicas: hay que fundar métodos, o explorar los que convengan más a este objeto. Los estudios particulares mismos ofrecen elementos para estas consideraciones; así, podemos reconocer qué objetos leen (qué tipo de publicaciones y qué aspectos de las publicaciones); desde dónde leen (historia, periodismo, historias - de la cultura, del periodismo, de la 86 literatura, estudios culturales, crítica cultural-); y por qué se leen: qué va a buscarse allí.

La investigación hemerográfica es un área de trabajo que ofrece posibilidades y perspectivas de estudio diversas. Las revistas constituyen un material inestimable para indagar en la historia y en las diversas manifestaciones culturales de una sociedad. En la perspectiva de Noemí Girbal de Blacha y Diana Quattrocchi-Woisson,

[...] las revistas pueden ser consideradas una fuente legítima del análisis histórico. [...] al combinar la actividad periodística y la iniciativa editorial, las revistas aparecen a menudo como

${ }^{23}$ Beatriz Sarlo, "Intelectuales y revistas: razones de una práctica", en América. Cahiers du CRICCAL, París, Université de la Sorbonne NouvelleParis III, Presses de la Sorbonne Nouvelle, p. 9-16; lo citado, p. 15. 
generadoras de cambios significativos en la esfera pública. Fueron y son también, registros de continuidades menos perceptibles y tal vez más duraderas que las derivadas del ámbito estrechamente político e institucional. Y [...] tuvieron necesariamente que ser eco, caja de resonancia y tribuna de los debates y combates que acompañaron este particular laboratorio que fue nuestro siglo $\mathrm{Xx}$, del cual emergieron y cristalizaron las grandes tradiciones políticas de la Argentina contemporánea. ${ }^{24}$

Emilia de Zuleta, en "Hacia un mapa de las revistas literarias argentinas", ${ }^{25}$ propone una serie de cuestiones que deben considerarse en la investigación: el hecho de que la revista tiene la "condición de órgano de un grupo"; los "aspectos institucionales implicados en su acción"; tales como la formación del grupo, los objetivos, los vínculos con otros proyectos; "la influencia que ejercen las revistas en la conformación del canon de lo que debe ser leído", y una atención sobre el receptor, por vía del "análisis riguroso de los mensajes" y de un "registro sobre tiradas y circulación" (p. 244-45). Además, apunta dos perspectivas para el estudio de las revistas: la diacrónica, en la que se periodiza la publicación y se señalan sus etapas, y la sincrónica, que la pone en relación con las otras publicaciones contemporáneas suyas.

Atendiendo a los aspectos que cubren los estudios hemerográficos particulares, se han distinguido los siguientes tipos de trabajos sobre revistas: índices, reproducciones facsimilares (con estudios o sin ellos), antologías y estudios sobre revistas. Índices, antologías y ediciones facsimilares favorecen y estimulan el estudio de una producción hemerográfica que no siempre resulta accesible. En el caso de los índices,

${ }^{24}$ Noemí Girbal de Blacha, Diana Quattrochi-Woisson, "Las revistas de debates y de combate: entre tradición política y empresa cultural", en Clio, 1997, Buenos Aires, $\mathrm{n}^{\circ}$ 4; lo citado, p. 13-4.

${ }^{25}$ Emilia de Zuleta, "Hacia un mapa de las revistas literarias argentinas", en Clío, 1997, Buenos Aires, Comité Argentino de Ciencias Históricas, Comité Internacional, ${ }^{\circ}$ 4, p. 243-256. 
éstos son, sin duda, muy útiles para otros tipos de estudios, porque permiten la búsqueda y la localización de escritos a partir de una amplia variedad de criterios (por tema, por autor, por tipo de texto, por fecha, etc.). Las antologías recogen una muestra, reducida por fuerza, pero permiten abrir un camino al conocimiento de las publicaciones. Las ediciones facsimilares, por su parte, nos proporcionan los textos originales de aquellas que son inasequibles, y también los paratextos, los dispositivos de impresión, y otros materiales que de igual forma transmiten información, como la publicidad. Sin embargo, estos recursos auxiliares no reemplazan el trabajo directo con las revistas. Aquí nos centraremos en el cuarto tipo de trabajo. En principio, respondiendo al recorte cronológico, se mencionarán especialmente los trabajos de considerable extensión o de importancia.

Cuentan con estudios las siguientes revistas del período señalado: Criterio (1928-), Los Raros (1920), Inicial (1923), Proa (1922-1923 y 1924-1926), La Campana de Palo (1925), Martín Fierro (19241927), Los Pensadores (1922-1924), Claridad(1926-1941) y Sintesis (1927-1930). Es posible que la enumeración, pese al deseo de que sea exhaustiva, resulte incompleta, dada la fragmentación y dispersión de

88 la investigación en la Argentina, lo que obstaculiza la recopilación bibliográfica.

\section{Criterio}

Sobre esta revista cultural de carácter católico, que comenzó a publicarse en 1928 y aún continúa, registramos tres trabajos, dos de ellos referidos al período mencionado. ${ }^{26}$

${ }^{26}$ Citamos aquí el tercer estudio referido a Criterio, porque no está dentro del decenio correspondiente a este trabajo: Marcelo Montserrat, "Criterio y una polémica doctrinal. El caso Maritain", Comité Argentino de Ciencias Históricas, Comité Internacional, Clío, 1997, Buenos Aires, n 4, p. 83-96. 
El primero, "Criterio" un periodismo diferente, de María Isabel De Ruschi Crespo, ${ }^{27}$ reseña la concepción del proyecto de Criterio, desde la propuesta de Atilio Dell'Oro Maini de hacer un periódico (semanario, aunque inicialmente se esbozó que fuera bisemanal) católico, la fundación de la empresa editorial Surgo, los objetivos de la publicación (el apostolado en la formación de un criterio cristiano para orientar la vida de los católicos), hasta su concreción. Si bien la Curia Eclesiástica tiene injerencia en cuestiones de dogma y moral, la Editorial Surgo es independiente y responsable en lo atinente a los asuntos ajenos al Magisterio de la Iglesia.

De Ruschi Crespo describe los números cero y uno de la publicación y las repercusiones en otros medios. Menciona a los colaboradores, distinguiendo entre ellos a los cristianos más comprometidos, y dedica una parte importante al ilustrador, Juan Antonio Spotorno.

El segundo es un breve estudio de María Ester Rapalo, que se centra en el período $1928-1931,{ }^{28}$ y señala que el cambio en 1930 de la dirección original imprime a la revista un tono más confesional y un discurso corporativo y antisemita.

\section{Los Raros}

Adolfo Prieto es el autor de un estudio sobre Los Raros (1920), considerada "Una curiosa 'Revista de orientación futurista"." ${ }^{29} \mathrm{Su}$ director, Bartolomé Galíndez, desarrolla un examen de las nuevas tendencias de

${ }^{27}$ María Isabel De Ruschi Crespo, "Criterio": un periodismo diferente. Génesis y fundación. Una respuesta católica al desafio de la prensa en la Argentina en la década de 1920, 1998, Buenos Aires, Grupo Editor Latinoamericano.

${ }^{28}$ María Ester Rapalo, "La Iglesia Católica argentina y el autoritarismo político: la revista Criterio, 1928-1931", en Anuario del IEHS, 1990, Tandil, $\mathrm{n}^{\circ}$ 5, p. 51-69.

${ }^{29}$ Adolfo Prieto, "Una curiosa 'Revista de orientación futurista", en $\mathrm{Bo}$ letín de Literaturas Hispánicas, 1961, Santa Fe, Universidad Nacional del Litoral, Facultad de Filosofía y Letras, $n^{\circ} 3$, p. 53-62. 
vanguardia en "un largo y caótico artículo de 43 páginas" (p. 56-7) del aparentemente único número de la revista. Aunque no es un documento literario importante, tiene un "valor testimonial nada desdeñable" (p. 59) para conocer cómo se vivió en Buenos Aires el impacto de las vanguardias europeas. Prieto transcribe pasajes del Manifiesto, también de Galíndez.

\section{Inicial}

Carlos Giordano ${ }^{30}$ examina los diez números de Inicial en relación con dos publicaciones contemporáneas, Martín Fierro y Proa. A diferencia de lo que se suele indicar, Giordano señala que Inicial, 'revista de ideas', no está comprendida en el modelo que configuran las otras dos revistas de vanguardia: "Aunque una parte de Inicial pareciera homóloga a la ideología común de Martín Fierro y Proa, no es esta parte [...] la que nos permitirá ubicarla, sino la que responde a su decidido anti-liberalismo" (p. 348).

Giordano cuestiona la distinción de dos etapas en la revista (una cercana a la vanguardia y otra más conservadora): "más bien, la caracterizaría una compacta coherencia, desde el comienzo hasta el final" (p. 348). La creación literaria ocupa un lugar escaso, sin una tendencia estética definida, con excepción de la muestra "Poesía americana de vanguardia", del número 10. En oposición a los artículos críticos, los ensayos sobre arte y literatura son extensos, y se distinguen por "una decidida actitud conservadora en materia artística, aunque, a veces, encubierta" (p. 350). No existen divisiones entre lo artístico, lo filosófico, lo político: la misma posición conservadora, reaccionaria, caracteriza la visión política, que impugna tanto al comunismo como a la democracia.

${ }^{30}$ Carlos Giordano, "La revista Inicial: Buenos Aires, 1923-1926", en América. Cahiers du CRICCAL. IV-V. Le discours culturel dans les revues latino-américaines de l'entre deux guerres, Paris, Université de la Sorbonne Nouvelle-Paris IIr, Presses de la Sorbonne Nouvelle, p. 347-57. 
Inicial sostuvo un peculiar nacionalismo, lejos del 'europeísmo modernista' como del 'criollismo primitivista'; respecto del latinoamericanismo, Inicial fue explícitamente contraria a la doctrina de Monroe y a la intervención de los Estados Unidos en los asuntos de América Latina.

Para Giordano, esta 'revista de jóvenes' parte de un "legítimo inconformismo ético" (p. 354) que derivará en el nacionalismo, el antisemitismo y el rechazo de la democracia liberal parlamentaria.

\section{Proa}

Ángel J. Battistessa publica una "Breve historia de una revista de vanguardia", ${ }^{31}$ referida a Proa (1924-1926). Destaca la labor de Ricardo Güiraldes, las dificultades en los apoyos y las colaboraciones, y la compara en su formato con Le Point, una revista parisina.

\section{Martín Fierro}

Sobre Martín Fierro (1924-1927), la revista más importante de la vanguardia porteña, hay numerosos trabajos; mencionamos cronológicamente los de Evar Méndez, ${ }^{32}$ Oliverio Girondo, ${ }^{33}$ Vera Beck, ${ }^{34}$ María Inés

31 Ángel J. Battistessa. "Breve historia de una revista de vanguardia", en Verbum. Revista del Centro de Estudiantes de Filosofia y Letras de Buenos Aires, Buenos Aires, nos. 2 y 3 (nueva época), diciembre de 1942. Recogido y ampliado con el título "Historia de una revista de vanguardia", en Idem. El prosista en su prosa, 1969, Buenos Aires, Nova, p. 147-58.

${ }^{32}$ Evar Méndez, [seudónimo de Evaristo González], 'La generación de poetas del periódico Martín Fierro", en Contrapunto. Literatura, crítica, arte, Buenos Aires, año I, $\mathrm{n}^{\circ}$ 5, agosto de 1945, p. 8-9, 13-4.

${ }^{33}$ Oliverio Girondo, El periódico Martín Fierro. 1924-1949, 1949, Buenos Aires.

${ }^{34}$ Vera Beck, "La revista Martín Fierro. Rememoración en su XXV aniversario", en Revista Hispánica Moderna, año XVI, nos. 1-4, enero-diciembre de 1950, p. 133-41. 


\section{MARÍA DEL CARMEN GRILLO}

Cárdenas de Monner Sans $^{35}$ y Emilio Carilla, ${ }^{36}$ Eduardo González Lanuza, ${ }^{37}$ Cayetano Córdova Iturburu, ${ }^{38}$ Beatriz Sarlo y Horacio Salas. ${ }^{39}$

Los autores plantean varias cuestiones: si la revista fue producida por un grupo de personas o por una generación, qué relación guarda su título con la obra homónima de José Hernández, qué participación le cupo en el desarrollo de los movimientos de vanguardia, qué relación mantuvo con otras publicaciones, afines o de signo contrario, cuáles fueron las polémicas que desató o en cuáles se involucró.

Respecto de si los participantes de Martín Fierro formaron o no parte de una generación, hay diversas posiciones.

Según Evar Méndez, su principal promotor, se trató de una 'generación', en tanto se produce

${ }^{35}$ María Inés Cárdenas de Monner Sans, “'Martín Fierro', revista, igrupo o generación?", en Universidad. Publicación de la Universidad Nacional del Litoral, Santa Fe, $\mathrm{n}^{\circ} 42$, octubre-diciembre de 1959, p. 5-23.

${ }^{36}$ Emilio Carilla, "El vanguardismo en la Argentina (Un periódico y un momento literario)", en Estudios de literatura argentina. (Siglo XX), 1961, Tucumán, Universidad Nacional de Tucumán, Facultad de Filosofía y Letras, Cuadernos de Humanitas, $n^{\circ}$ 6, p. 33-60.

${ }^{37}$ Eduardo González Lanuza, "Detalle del contenido de Martín Fierro", en su Los martinfierristas, 1961, Buenos Aires, Ediciones Culturales Argentinas.

${ }^{38}$ [Cayetano] Córdova Iturburu, La revolución martinfierrista, 1962, Buenos Aires, Ediciones Culturales Argentinas.

${ }^{39}$ Horacio Salas, "Estudio preliminar", en Revista Martín Fierro: 19241927. Edición facsimilar, [c: 1995], Buenos Aires, Fondo Nacional de las Artes. Agregamos aquí dos estudios que no exponemos en el cuerpo de la ponencia: José Luis Trenti Rocamora, Índice general y estudio de la revista "Martín Fierro" (1924-1927), 1996, Buenos Aires, Sociedad de Estudios Bibliográficos Argentinos, Ediciones Dunken, serie "Estudios", $\mathrm{n}^{\circ}$ 1; José Luis Trenti Rocamora, Presencia uruguaya en la revista "Martín Fierro" Buenos Aires 1924/1927, 1997, Buenos Aires, Sociedad de Estudios Bibliográficos Argentinos, Ediciones Dunken, serie "Presencias americanas", suplemento $\mathrm{n}^{\circ} 1$. 
la presencia, en momento determinado, de una promoción de hombres de letras, que, además de parejo número de años jóvenes, dotados de la impulsiva savia renovadora inherente, y esto es lo importante, coincide en las mismas ideas, adopta una orientación similar, embandera un ideal común. (n. 1, p. 8)

Cárdenas se pregunta si el Martín Fierro de 1924 puede definir una generación literaria tal como lo entiende José Ortega y Gasset. En su opinión, el hecho de que sólo sea una publicación literaria y artística la limita en sus 'proyectos vitales' y le impide "que el grupo o cenáculo pueda convertirse en generación" (p. 13) o en escuela literaria. Lo considera más bien un grupo alejado de las 'circunstancias' en el sentido de Ortega y Gasset, tanto de lo que pasaba en el país como de las particularidades que definen a una generación.

Carilla le dedica a Martín Fierro un capítulo de sus Estudios de literatura argentina. Del vanguardismo argentino, trasladado a su vez de las vanguardias europeas, destaca dos revistas, Proa y Martín Fierro, aunque le concede el lugar más visible a la segunda; para Carilla, no es 1922 el año decisivo que inaugura el vanguardismo, sino 1924, ya que es el año en que comienzan a publicarse las dos revistas. Además, Carilla termina por identificar vanguardismo argentino con martinfierrismo, ${ }^{40}$ ya que "ninguna otra publicación de este tipo alcanzó entre nosotros las dimensiones (singularidad, reflejo, espectacularidad, (etc.)", de esta publicación (p. 45).

Según González Lanuza, la duración de Martín Fierro permitió la configuración de un 'movimiento', y la dirección de Evar Méndez "[...] mantuvo una publicación generacional de una generación a la que no pertenecía" (p. 30), porque superaba en edad a los demás.

El periódico Martín Fierro. 1924-1949, redactado por el poeta Oliverio Girondo con ocasión de cumplirse los 25 años de la aparición de

${ }^{40}$ Emilio Carilla, op. cit., cfr., p. 59; Carilla ha apuntado más arriba: "[...] es prueba de su importancia el hecho de que de allí haya salido el nombre de Martinfierrismo como uno de los nombres singularizadores de la época" (p. 57). 
la revista, intenta rectificar algunas afirmaciones que alteraron la verdad sobre la revista. Señala que fue, ante todo, un periódico literario, que estuvo "tan arraigado en la tradición como en la realidad del país y del mundo" (p. 18). La revista, en opinión de Girondo, "nunca estructuró una estética propia" (p. 45).

Los martinfierristas no sólo se interesaron por la literatura, sino también por otras manifestaciones artísticas: la música (el jazz), el cine, el arte y la arquitectura. Sin embargo, Carilla destaca que, pese a su carácter artístico, la tendencia más notoria fue la literaria; Salas concuerda con estos pareceres, pero señala que la revista no reconoció el teatro de Armando Discépolo, el grotesco.

Con respecto al nombre, Evar Méndez recuerda: "Tomó ese nombre del poema tradicional porque la de José Hernández es una obra de no-conformidad [...] como un símbolo de argentinismo neto, no de criollismo ni de 'folklore'. Obra de emancipación" (p. 8).

Cárdenas historia las tres publicaciones llevaron el mismo título que la que nos ocupa: una de 1876, que se opuso a la política de Adolfo Alsina; otra anarquista, de 1904, dirigida por Alberto Ghiraldo, y una de 1919, también impulsada por Evar Méndez.

94 Beck examina la importancia de Martín Fierro para la ideología de la vanguardia argentina. En su parecer, la publicación encontró un ambiente desfavorable a la vanguardia y se hermanó con otras revistas vanguardistas: Inicial, Valoraciones, Noticias Literarias, Teseo, Cruz del Sur.

Una de sus características más notoria fue la polémica: con Boedo, con Manuel Gálvez y la nueva generación, y sobre Leopoldo Lugones. Beck apunta: "Fiel a su programa de veracidad y de libertad de expresión, la dirección de Martín Fierro no sólo permite el iconoclasmo cuando se trata de un ídolo, sea nacional o de prestigio internacional [...], sino también ofrece lugar a opiniones contrarias" (p. 139).

Cayetano Córdova Iturburu relata en La revolución martinfierrista sus recuerdos sobre la revista desde el esbozo original: "decidida, fundamentalmente, a alzar el palo de la crítica, sin reservas, sobre cuanta indignidad ambulara por el mundo, sin distinción de fronteras o de actividades" (p. 10). 
Carilla destaca que sus escritores, por primera vez en el periodismo literario argentino, utilizaron una crítica "que pasa con frecuencia del análisis severo a la burla y a la sátira", y que era muestra de sus reconocimientos y rechazos.

Uno de los temas más abordados en la historia de las vanguardias en la Argentina es el de la confrontación Florida-Boedo; Florida, calle cosmopolita y brillante, representa al grupo de Martín Fierro, vanguardista y cultor del arte por el arte; Boedo, la avenida de una zona popular, es la denominación de un grupo que aboga por un arte liberador, al servicio del pueblo.

Méndez relata que Martín Fierro no sólo condujo las nuevas tendencias de vanguardia en la Argentina, sino que atrajo a los escritores realistas de Boedo, considerados como sus opuestos: "no podían negarlo Barletta, Teatro del Pueblo, 'Conducta', en ciertos aspectos modernos" (p. 9).

Para Salas, esta confrontación quedó solamente en bromas y algunos insultos, pero careció de un 'real basamento ideológico' (p. XIII). Sin embargo, otros autores enfatizan que el enfrentamiento fue tal.

Agudamente, Beatriz Sarlo señala que esta polémica con Boedo, en realidad, encubre, además de cuestiones estéticas, una ambivalente relación entre la vanguardia y el mercado: “[...] en el rechazo del mercado, Martín Fierro une la condena moral ante el lucro y la refutación de una estética 'inferior'. Si el surgimiento del mercado de obra literarias tiene que ver con la ampliación del público, el problema de la vanguardia es, invariablemente, cómo dividirlo" (p. 147-8).

\section{La Campana de Palo}

Nilda Díaz describe los números de la primera época de La Campana de Palo, ${ }^{41}$ y destaca su distancia frente a Florida y a Boedo. Respecto de

${ }^{41}$ Nilda Díaz, "La Campana de Palo - Primera época", en América. Cahiers $d u$ CRICCAL, París, Université de la Sorbonne Nouvelle-Paris III, Presses de la Sorbonne Nouvelle, nos. IV-V; Le discours culturel dans les revues latinoaméricaines de l'entre deux guerres, p. 359-68. 
Florida, en rechazo a su pasatismo, su trivialidad, su visión del arte por el arte y su indiferencia frente al problema social; de Boedo, por su concepción de una literatura social "que va del realismo patológico a la truculencia pornográfica", 42 para La Campana de Palo "es posible escribir una literatura realista, social, y evitar las trampas del naturalismo" (p. 363), señala Díaz.

Sus duras críticas se dirigen no sólo a la creación literaria sino a otras manifestaciones artísticas; en política, las críticas se dirigen a todas las tendencias, excepto a la anarquista:

Por tenue y diluído [sic] que sea su perfil, por contradictorios y ambiguos que aparezcan algunos enunciados, no es menos cierto que las líneas laudatorias dedicadas a Barret por Juan Guijarro(s), los extractos de su Barret sintético, así como el calificativo, repetidas veces aplicado a Tolstoi, de anarquista o anarquista cristiano, tiende a poner de relieve ciertos valores que se ubicarían dentro de un modelo anarquista, teñido con una buena dosis de utopía socialo-humanitaria [sic] (p. 366).

\section{Los Pensadores y Claridad}

96 Los Pensadores (1922-1924 y 1924-1926) y Claridad (1926-1941) forman parte de la misma empresa editorial de Antonio Zamora. Los Pensadores. Publicación de obras selectas fue un cuaderno semanal que difundió en ediciones económicas obras de la literatura universal. A partir del número 101, en diciembre de 1924, comienza su segunda época: se convierte en una revista literaria, y su subtítulo cambia por el de Arte, Critica y Literatura. Los Pensadores termina en 1926 con 122 números; en ese mismo año comienza a salir Claridad, que reanuda la numeración de su antecedente: llegó a publicar 225 números que, sumados a los 122 de Los Pensadores, totalizan 347.

Sobre estas dos revistas de la editorial de Antonio Zamora conocemos los trabajos publicados en un número especial de la revista Todo

42 "Florida y Boedo", La Campana de Palo, año I, n 4, p. 4, en Capítulo. La historia de la literatura argentina, "Serie Complementaria; Ediciones facsimilares", 1982, Buenos Aires, Centro Editor de América Latina. 
es Historia, y los estudios de Graciela Montaldo, Nicolás Jorge Dornheim, Liliana Cattáneo y Florencia Ferreira de Cassone.

La revista de divulgación Todo es Historia ${ }^{43}$ dedicó un número a Claridad, con varios artículos ${ }^{44}$ que recuerdan la importancia de la editorial Claridad en el proyecto liderado por Antonio Zamora, el cual incluyó diversas colecciones bibliográficas a precios bajos; los antecedentes de la revista, tanto las dos que llevaron el mismo nombre en 1920 y 1921 (ambas socialistas), como Los Pensadores, la publicación de Zamora que precedió a Claridad; el infrecuente sistema de distribución (en puestos callejeros y quioscos de la ciudad), y su declinación en la Segunda Guerra Mundial.

Graciela Montaldo ha dedicado tres trabajos a Los Pensadores y a Claridad. ${ }^{45}$ En ellos, se ocupa de los proyectos editoriales y culturales de la izquierda en la Argentina, basados sobre todo en el desarrollo de una educación popular por medio de la lectura.

Este proyecto 'ecléctico' implica una concepción moral del arte y de la literatura: "hay [...] un criterio que hegemoniza las elecciones y que funda la poética de la CEC: la literatura - pero el arte en general-es fundamentalmente un contenido, una idea, una doctrina" ("La literatura como pedagogía...", p. 47). Montaldo sostiene que este proyecto

${ }^{43}$ Todo es Historia, Buenos Aires, año XV, n 172, septiembre de 1981. ${ }^{44}$ José Barcia, "Claridad', una editorial del pensamiento", cit., p. 8-25; Ernesto Giudici, "Claridad' en la década del 30", cit., p. 26-45; EJC (E[milio] J. C[orbière]), "Recuerdos de Antonio Zamora" y "Dos antecedentes en la historia de Claridad", cit., p. 38-9 y 46, respectivamente.

${ }^{45}$ Graciela Montaldo, "La literatura como pedagogía, el escritor como modelo. Cooperativa Editorial Claridad: proyecto cultural y empresa comercial", en Cuadernos Hispanoamericanos, Madrid, $n^{\circ} 445$, julio de 1987, p. 41-64; Graciela Montaldo, "Los Pensadores y Claridad. Una propuesta cultural de la izquierda argentina (1922-1941)"; Graciela Montaldo, "Literatura de izquierda: humanismo y pedagogía", en Graciela Montaldo (Dir. del tomo) Yrigoyen, entre Borges y Arlt (1916-1930). Historia social de la literatura; David Viñas (Dir. general), [1989], Buenos Aires, Editorial Contrapunto, t. VII, p. 367-91. 
careció de una definición, y aunque en la Argentina recibió críticas por igual de la izquierda partidaria como de los sectores que suscribían una cultura o un arte menos comprometidos ideológicamente, tuvo un estrecho intercambio con intelectuales y políticos latinoamericanos, y fue "una de las pocas formaciones de intelectuales argentinos que se hizo cargo de la propuesta latinoamericana" (Los Pensadores y Claridad, p. 422).

En cuanto a las polémicas entre Boedo y Florida, Montaldo explica que ésta no fue la única: los veristas se enfrentaron contra los escritores de folletín, contra los editores de obras de la literatura universal en publicaciones recortadas, alteradas, contra el periodismo, sobre todo la llamada 'prensa amarilla' (el diario Critica).

Dornheim recupera en "Las letras alemanas en la revista porteña 'Claridad' (1926-1941)"46 la actuación que el órgano desempeñó en la difusión de la literatura alemana, sobre todo en 1929, con ocasión de la visita del conde de Keyserling a Buenos Aires, y en 1932, año del centenario del fallecimiento de Johann Wolfgang von Goethe. La obra de Stefan Zweig y la literatura pacifista (como Sin novedad en el frente de Erich María Remarque) también fueron motivos de contacto con la literatura alemana: ediciones, biografias y adelantos de Zweig, y en el caso de Remarque, tanto la crítica literaria, como la edición económica de la novela.

Además, Dornheim recuerda la postura antinazi que Claridad sostuvo desde junio de 1933 (número 266), y su apoyo a la literatura contraria al régimen.

"La revista Claridad: una tribuna latinoamericana de la izquierda argentina" de Cattáneo ${ }^{47}$ describe la importancia de esta publicación

${ }^{46}$ Nicolás Jorge Dornheim, "Las letras alemanas en la revista porteña 'Claridad' (1926-1941)", en Boletín de literatura comparada. Actas "Hacia una historia de la literatura comparada en la Argentina", Mendoza, Universidad Nacional de Cuyo, año XIII-XV, 1988-1990, p. 265-77.

${ }^{47}$ Liliana Cattáneo, "La revista Claridad: una tribuna latinoamericana de la izquierda argentina". 
en la difusión y los debates de las diversas tendencias de izquierda argentinas y latinoamericanas. En los años treinta, Claridad abandona una posición estética "para encarar más decididamente la polémica ideológica" (p. 172).

Tres acontecimientos mundiales concitaron la atención de Claridad en ese decenio: el fascismo, el stalinismo y el New Deal de Franklin D. Roosevelt. Hacia 1936, la revista pasa a 'alinearse' con Roosevelt y en enero de 1937 se subtitula "La Revista Americana de los Hombres Libres" en vez de "Tribuna del Pensamiento Izquierdista". A la crítica permanente al imperialismo norteamericano y a sus intervenciones en los demás países de América le sucede una condena a la llamada 'plutocracia yanqui' cuando Roosevelt es reelegido por primera vez para presidente de los Estados Unidos, y en diciembre de 1936 la revista le dedica un número.

Florencia Ferreira de Cassone, en una ponencia y en una edición de su tesis doctoral, "Claridad y el 6 de septiembre de 1930" y Claridad $y$ el internacionalismo americano, ${ }^{48}$ se aboca exhaustivamente al estudio de la revista.

En "Claridad y el 6 de septiembre de 1930" Ferreira de Cassone estudia el papel que desempeñó la revista en la caída de la presidencia de Hipólito Yrigoyen. Para ello, se remonta al enfrentamiento permanente entre la Unión Cívica Radical y el Partido Socialista. Las críticas hacia la segunda presidencia del radical Yrigoyen fueron insistentes, sobre todo por "no haber producido cambios sustanciales en la estructura social y económica argentina" (p. 64), por mantener la política de caudillos y grupos de obsecuentes. Después del golpe militar de septiembre contra Yrigoyen, los socialistas de Claridad advirtieron muy pronto con persecuciones, arrestos y deportaciones (por ejemplo al director, Antonio Zamora) que las libertades estaban cercenadas.

${ }^{48}$ Florencia Ferreira de Cassone, "Claridad y el 6 de septiembre de 1930", Comité Argentino de Ciencias Históricas, Comité Internacional, Clío, 1997, Buenos Aires, $n^{\circ} 4$, p. 59-81; Florencia Ferreira de Cassone, Claridad y el internacionalismo americano, 1998, Buenos Aires, Editorial Claridad. 
En Claridad y el internacionalismo americano, Ferreira se aboca principalmente al estudio del internacionalismo iberoamericano, el imperialismo y la reforma universitaria, y examina las relaciones entre Claridad y los países latinoamericanos (Perú, Bolivia, Ecuador; Paraguay, Brasil, Chile, Uruguay; Cuba, Puerto Rico, República Dominicana, Haití; México; Colombia y Venezuela).

La autora considera que Claridad "ofrece un mirador de extraordinario interés para conocer el desarrollo del movimiento revolucionario de izquierda en nuestra América":

a través de la Revista Claridad se manifestó la intención de los movimientos revolucionarios de promover una acción internacional, sobre la base de la difusión de sus programas y de la propuesta de una militancia conjunta para llevar a cabo objetivos políticos comunes a dichos sectores ideológicos (p. 19-20).

Ferreira subraya que Claridad fue pionera en incorporar la preocupación por América, lo que la diferenciaba, por ejemplo, del órgano del Partido Socialista, La Vanguardia:

Esta presencia americana fue una novedad en el periodismo y en el pensamiento político argentino, el cual, ha estado y está preferentemente dedicado a la perspectiva nacional o, en todo caso, a la temática europea. Cuando Claridad comenzó su campaña, Iberoamérica era un tema exótico, incluso para los revolucionarios que, en teoría, tenían en cuenta la proyección americana de la revolución (p. 290). 
REVISTAS CULTURALES ARGENTINAS

\section{Sintesis}

Sobre Síntesis (1927-1930), mencionamos el estudio e índice de David Roger Dowdy ${ }^{49}$ y el de María Silvia Ospital, titulado "Sintesis: artes, ciencias y letras". 50

Ospital considera que la revista fue "un espacio de debate más amplio que el meramente académico" (p. 56). Su hispanismo, la defensa de la tradición y de la identidad cultural argentina e hispanoamericana no limitaron los temas y asuntos considerados, ni la presencia de colaboradores de diferente signo: "Junto a ex-martinfierristas como Borges y Rojas Paz, trabajaron escritores no vanguardistas (Arturo Capdevila); al mismo tiempo, figuras más o menos bohemias compartieron espacios comunes con sólidos representantes institucionales como Alberini y Ravignani" (p. 51).

En relación con la política, aunque miraron con agrado la presencia en Buenos Aires de Ramiro de Maeztu como embajador español de la dictadura de Primo de Rivera, la revista tuvo una clara posición democrática, tan así es que en octubre de 1930 dejó de editarse. A juicio de Ospital, las contradicciones de la revista le impidieron mantenerse:

Es tal vez en esta combinación de elementos contrapuestos que deben buscarse las causas de su incapacidad para sobrevivir en la nueva etapa abierta en 1930, luego de haber construido un espacio cultural sólido y reconocido y de haberlo mantenido por un lapso considerable (p. 58).

${ }^{49}$ David Roger Dowdy, A study and index of "Síntesis: Revista argentina de artes, ciencias y letras" (1927-1930), 1976, University of Missouri, Thesis.

${ }^{50}$ María Silvia Ospital, "Sintesis: artes, ciencias y letras”, Comité Argentino de Ciencias Históricas, Comité Internacional, Clio, 1997, Buenos Aires, $\mathrm{n}^{\circ}$ 4, p. 47-58. 
MARÍA DEL CARMEN GRILLO

\section{Consideraciones finales}

Todos estos estudios han sido encarados desde la historia argentina y desde la literatura, y la mayor parte de las veces son descripciones del contenido. Aún falta en la Argentina la investigación de las revistas desde un enfoque que integre perspectivas y que sea pertinente también desde el punto de vista de los estudios de comunicación.

El decenio 1920-1930 es decisivo para el estudio de las revistas culturales no sólo porque las revistas hayan sido el principal factor de difusión de las vanguardias y de líneas ideológicas combativas de izquierda, sino también porque la sociedad consumía gran cantidad de publicaciones: folletos, periódicos, revistas y libros (en diferentes calidades de edición - buena parte de lo publicado es lo que Luis Alberto Romero ha llamado 'libros baratos'-51), a pesar de que el cine y la radio ya habían comenzado a competir con esta cultura de la letra impresa. $^{52}$

También interesa el estudio de las revistas desde el punto de vista del público lector: éste crece en número y demanda productos diversificados; Luis A. Romero y Leandro H. Gutiérrez describen la situación respecto de los sectores populares en "La cultura de los sectores populares porteños (1920-1930)".53

${ }^{51}$ Luis Alberto Romero, Libros baratos y cultura de los sectores populares, 1986, Buenos Aires, CISEA.

${ }^{52} \mathrm{Cfr}$. Jorge Rivera, "Historia indiscreta de la edición argentina", en $L a$ Caja. Revista del ensayo negro, Buenos Aires, $n^{\circ} 10, \mathrm{p}$. 13-5: "La incipiente trama de lectura originada por la proliferación de folletines periodísticos, folletería de kiosco, revistas, ediciones minimalistas y libros de bajo precio ('no querida' por supuestamente 'banalizadora' desde la perspectiva letrada), generó adhesiones y usufructuos ambivalentes, como los de Gálvez, y repulsas francamente planteadas desde una perspectiva clasista"; lo citado, p. 14.

${ }^{53}$ Luis A. Romero y Leandro H. Gutiérrez, "La cultura de los sectores populares porteños (1920-1930)", en Espacios de Crítica y Producción, Buenos Aires, $\mathrm{n}^{\circ}$ 2, julio-agosto de 1985, p. 3-6. 
Cada corriente responde a un segmento de una cultura heterogénea y fragmentaria, donde se mezclan la valoración de la 'alta cultura' y la búsqueda de conocimientos útiles para la vida familiar o laboral, el deseo de conocer la realidad social y de denunciar sus injusticias, la mera apetencia de evasión y entretenimiento y la búsqueda de formación política (p. 5).

Todo este período ha sido descripto por Jorge Rivera como el de la 'industria cultural', caracterizado por la conciencia de los intelectuales acerca de su propia actividad, lo que se ha llamado la "profesionalización del escritor"; 54 por recientes empresas editoriales, que desarrollan diversos proyectos, muchos de ellos con vocación de totalidad (como las diversas colecciones de obras, publicadas periódicamente), y por una naciente clase media urbana, alfabetizada, que configura un público ávido de cultura.

${ }^{54}$ Cfr. Beatriz Sarlo, "Vanguardia y criollismo: la aventura de Martín Fierro", en Carlos Altamirano y Beatriz Sarlo, Ensayos argentinos: de Sarmiento a la vanguardia, 1983, Buenos Aires, Centro Editor de América Latina, p. 127-71. 